\title{
Polymorphisms in nitric oxide synthase and endothelin genes among children with obstructive sleep apnea
}

Siriporn Chatsuriyawong ${ }^{1,2}$, David Gozal ${ }^{1}$, Leila Kheirandish-Gozal ${ }^{1}$, Rakesh Bhattacharjee ${ }^{1}$, Ahamed A Khalyfa ${ }^{1}$, Yang Wang ${ }^{1}$, Wasana Sukhumsirichart ${ }^{2}$ and Abdelnaby Khalyfa ${ }^{1 *}$

\begin{abstract}
Background: Obstructive sleep apnea (OSA) is associated with adverse and interdependent cognitive and cardiovascular consequences. Increasing evidence suggests that nitric oxide synthase (NOS) and endothelin family $(E D N)$ genes underlie mechanistic aspects of OSA-associated morbidities. We aimed to identify single nucleotide polymorphisms (SNPs) in the NOS family (3 isoforms), and EDN family (3 isoforms) to identify potential associations of these SNPs in children with OSA.

Methods: A pediatric community cohort (ages 5-10 years) enriched for snoring underwent overnight polysomnographic (NPSG) and a fasting morning blood draw. The diagnostic criteria for OSA were an obstructive apnea-hypopnea Index (AHI) $>2 / h$ total sleep time (TST), snoring during the night, and a nadir oxyhemoglobin saturation $<92 \%$. Control children were defined as non-snoring children with AHI $<2 / \mathrm{h}$ TST (NOSA). Endothelial function was assessed using a modified post-occlusive hyperemic test. The time to peak reperfusion (Tmax) was considered as the indicator for normal endothelial function (NEF; Tmax $<45 \mathrm{sec}$ ), or ED (Tmax $\geq 45 \mathrm{sec}$ ). Genomic DNA from peripheral blood was extracted and allelic frequencies were assessed for, NOS1 (209 SNPs), NOS2 (122 SNPs), NOS3 (50 SNPs), EDN1 (43 SNPs), EDN2 (48 SNPs), EDN3 (14 SNPs), endothelin receptor A, EDNRA, (27 SNPs), and endothelin receptor B, EDNRB (23 SNPs) using a custom SNPs array. The relative frequencies of NOS-1,-2, and -3 , and EDN-1,-2,-3,-EDNRA, and-EDNRB genotypes were evaluated in 608 subjects [128 with OSA, and 480 without OSA (NOSA)]. Furthermore, subjects with OSA were divided into 2 subgroups: OSA with normal endothelial function (OSA-NEF), and OSA with endothelial dysfunction (OSA-ED). Linkage disequilibrium was analyzed using Haploview version 4.2 software.
\end{abstract}

Results: For NOSA vs. OSA groups, 15 differentially distributed SNPs for NOS1 gene, and 1 SNP for NOS3 emerged, while 4 SNPs for EDN1 and 1 SNP for both EDN2 and EDN3 were identified. However, in the smaller sub-group for whom endothelial function was available, none of the significant SNPs was retained due to lack of statistical power.

Conclusions: Differences in the distribution of polymorphisms among NOS and EDN gene families suggest that these SNPs could play a contributory role in the pathophysiology and risk of OSA-induced cardiovascular morbidity. Thus, analysis of genotype-phenotype interactions in children with OSA may assist in the formulation of categorical risk estimates.

Keywords: Children, OSA, Nitric oxide synthase (NOS), Endothelin (EDN), SNP, Polymorphisms

\footnotetext{
*Correspondence: akhalyfa@uchicago.edu

'Department of Pediatrics, Comer Children's Hospital, Pritzker School of

Medicine, Biological Sciences Division, The University of Chicago, 900 E, 57th

Street, KCBD, 4112, Chicago, IL 60637, USA

Full list of author information is available at the end of the article
} 


\section{Background}

Obstructive sleep apnea (OSA), is the most prevalent form of sleep disordered breathing both in adults and children [1-3] and has been associated with significant neurocognitive, metabolic, and cardiovascular morbidities [4-8]. OSA is characterized by episodes of total and/or partial collapse of the upper airway alternating with normal breathing during sleep, leading to chronic intermittent hypoxia and hypercapnia, sleep fragmentation and increased swings in intrathoracic pressures. This condition may affect $1-3 \%$ of healthy school-aged children [2]. There is accumulating evidence that OSA is strongly linked to cardiovascular morbidity independent of obesity [9-11]. The presence of altered endothelial function is currently viewed as an early risk marker of cardiovascular disease, and is a relatively common occurrence in both adult and pediatric patients with OSA [12-14], and can precede the onset of hypertension [15]. However, not every child with OSA will develop ED, suggesting that genetic factors may play a role.

Nitric oxide synthase (NOS) is encoded by three distinct genes, namely neuronal NOS (nNOS, NOS1), inducible NOS (iNOS, NOS2), and endothelial NOS (eNOS, NOS3), which are located on chromosomes 12, 17 and 7, respectively. Studies have examined the possibility that SNPs in these genes may influence their expression and functional activity, and potentially alter the predisposition to cardiovascular disease [16-18]. Accordingly, single nucleotide polymorphisms (SNPs) have been identified in NOS genes, and their association with coronary artery disease, hypertension, and diabetes has been explored [19-22]. Considering the potential role of these enzymes in either OSA or its downstream adverse consequences, it is somewhat surprising that the potential associations between NOS polymorphisms and OSA remain thus far unexplored.

The endothelins $(E D N)$ are a family of endotheliumderived peptides that possess vasoconstrictor properties, and are important mediators of both physiological and pathophysiologic processes [23]. The genes encoding for $E D N-1,-2$ and-3 are located on chromosomes 6, 1, and 20, respectively [24]. Several studies have been identified various SNPs on $E D N$ genes and also in the genes encoding for their cognate receptors (EDNRA and $E D N R B)$, and some of these gene variants have been associated with altered susceptibility and prognosis of diseases such as heart failure, dilated cardiomyopathy, diabetic retinopathy, and atherosclerosis [25-31]. Furthermore, genetic polymorphisms in the endothelin-receptor-subtype-A (EDNRA) gene have been identified as conferring increased susceptibility for OSA in adults [32].

Based on aforementioned considerations, we hypothesized that single nucleotide polymorphisms (SNPs) in $N O S$ - and $E D N$-related genes in children may contribute to the risk of pediatric OSA or its downstream vascular consequences.

\section{Methods \\ Subjects}

The study was approved by the University of Louisville Human Research Committee, and informed consent was obtained from the legal caretaker of each participant. Consecutive healthy pre-pubertal children (ages 5-10 years) were recruited from the community, and the cohort was enriched for the presence of habitual snoring. All children underwent a standard polysomnographic evaluation in the sleep laboratory at the University of Louisville Pediatric Sleep Laboratory, after which assessment of endothelial function (when possible) and a blood draw were performed between 7:00 to 8:00AM in fasting conditions.

\section{Overnight polysomnography}

A standard overnight multichannel polysomnographic evaluation was performed in the sleep laboratory as described previously [33]. Sleep architecture was assessed by standard techniques [34]. The proportion of time spent in each sleep stage was expressed as percentage of total sleep time (\%TST). Obstructive apnea was defined as the absence of airflow with continued chest wall and abdominal movement for duration of at least two breaths [33]. Hypopneas were defined as a decrease in oronasal flow of $\geq 50 \%$ with a corresponding decrease in $\mathrm{SpO}_{2}$ of $\geq 4 \%$ and/or arousal [33]. The obstructive apnea/hypopnea index was defined as the number of apneas and hypopneas per hour of TST. Arousals were defined as recommended [35] and included respiratory-related (occurring immediately following an apnea, hypopnea, or snore), technician-induced, and spontaneous arousals. Arousals were expressed as the total number of arousals per hour of sleep time (arousal index). Control children required the presence of an $\mathrm{AHI}<2$ in the absence of a history of snoring as well as no snoring detected during the sleep study. Habitually snoring children with AHI $>2 /$ hrTST and a nadir oxyhemoglobin saturation $<92 \%$ were considered to have OSA [33].

\section{Body mass index}

Children were weighed using the InBody 320 scale (Biospace; Cerritos, CA), and height (to $0.1 \mathrm{~cm}$ ) was measured using a stadiometer (Holtain, Crosswell, UK). The BMI was calculated and the BMI $z$-score was computed using US Centers for Disease Control and Prevention 2000 growth standards (http://www.cdc.gov/growthcharts/) and online software (http://wwwn.cdc.gov/epiinfo/). A BMI $z$-score $>1.65$ ( $>95$ th percentile) was considered as fulfilling obesity criteria. 


\section{Sphygmomanometry}

All children had arterial blood pressure measured noninvasively using an automated mercury sphygmomanometer (Welch Allyn; Skaneateles Falls, New York) at the brachial artery, using the appropriate cuff size on the non-dominant arm.[36] Systolic BP and diastolic BP indices were calculated by dividing the average systolic and diastolic pressure by the respective 95th percentile for BP using National Heart, Lung and Blood Institute guidelines http://www.nhlbi.nih.gov/guidelines/hypertension/ child_tbl.htm), computed for age, sex, and height. Hypertension was defined when the SBPi or DBPi was $>1$.

\section{Endothelial function tests}

Endothelial function was assessed upon awakening from the sleep study in the morning, using a modified hyperemic test after cuff-induced occlusion of the radial and ulnar arteries as previously described $[14,15,37,38]$. Briefly, a laser Doppler sensor (Periflux 5000 System, Perimed, Jarfalla, Sweden) was applied over the volar aspect of the hand at the 1st finger distal metacarpal surface and the hand was gently immobilized. Once cutaneous blood flow over the area became stable, the pressure within an inflatable cuff placed at the forearm and connected to a computer-controlled manometer was raised to $200 \mathrm{mmHg}$ for $60 \mathrm{sec}$ during which blood flow was reduced to undetectable levels. The cuff was rapidly deflated and the laser Doppler measured hyperemic responses. As previously shown, the time to peak regional blood flow after occlusion release (Tmax) is highly reproducible and is representative of the postocclusion hyperemic response, an index of endothelial function [39]. A Tmax value $\geq 45 \mathrm{sec}$ was considered as the criterion for abnormal endothelial function as previously described $[9,10,14,15,37,38]$.

\section{DNA extraction}

Peripheral blood samples were collected in vacutainer tubes containing EDTA (Becton Dickinson, Franklin Lakes, NJ, USA). All DNA samples were extracted using QIAmp DNA blood kit (Qiagen, Valencia, CA) according the manufacturer's protocol. The concentration and quality of the DNA were determined using a ND-1000 Spectrophotometer (Nanodrop Technologies, Wilmington, DE, USA). The precise length of genomic DNA was determined by gel electrophoresis using $1 \%$ agarose gel. All the purified samples were stored at $-80^{\circ} \mathrm{C}$ until further analyses.

\section{Custom cardiovascular gene SNP array}

The IBC array was developed using SNP and linkage disequilibrium information from the HapMap as well as data from Seattle SNPs, and National Institute of Environmental Health Sciences (NIEHS) SNPs [40]. Briefly, the IBC array contains about 50,000 SNPs from genetic diversity across approximately 2100 genes related to cardiovascular, inflammatory, hemostasis/coagulation, and metabolic phenotypes and pathways. Among those genes, we selected the NOS genes which include NOS1 (209 SNPs), NOS2 (122 SNPs) and NOS3 (50 SNPs). Furthermore, we selected the EDN and EDN receptor genes family which includes EDN1 (43 SNPs), EDN2 (48 SNPs), EDN3 (14SNPs), EDNRA (27 SNPs) and EDNRB (23 SNPs). SNPs were clustered into genotypes with the Illumina Beadstudio software and subjected to qualitycontrol filters at the sample and SNP levels separately within each cohort. Samples were excluded for individual call rates $<90 \%$, gender mismatch, and duplicate discordance. SNPs were removed for call rates $<95 \%$ or Hardy-Weinberg Equilibrium $\mathrm{p}<10^{-7}$ in controls from each cohort (regardless of ethnicity). Due to the lowfrequency SNPs included in the design and the aim to capture low-frequency variants of large effect across the large dataset, we filtered only on minor allele frequency $(\mathrm{MAF})<0.005$.

\section{Total RNA isolation}

Fasting peripheral blood samples were drawn from children within the first hour after awakening and collected in PAXgene Blood RNA tubes (Becton Dickinson, UK). Total RNA was isolated using PAXgene Blood RNA Kit and treated with DNase I (QIAGEN, CA), according to the manufacturer's protocol. The RNA quantity and integrity were determined using a Nanodrop Spectrophotometer and Agilent 2100 Bioanalyzer Nano 6000 LabChip assay (Agilent Technologies, Santa Clara, CA).

\section{qPCR validation}

Quantitative real-time PCR (QRT-PCR) were performed using the ABI 7500 instrument (Applied Biosystems, Foster City, CA). Complementary DNA was synthesized using a High-Capacity cDNA Archive Kit (Applied Biosystems, Foster City, CA). Five hundred nanograms (500 ng) of total RNA from NOSA and OSA samples were used to generate cDNA templates for RT-PCR with primer specific for EDN1 gene. The TaqMan ${ }^{\circledR}$ Master Mix Reagent Kit (Applied Biosystems, Foster City, CA) was in $25 \mu \mathrm{l}$ reactions. Various negative controls were included in the PCR reaction to ensure specific amplification. Triplicate PCR reactions were performed in 96well plates for each gene in parallel with the 18S rRNA. The steps involved in the reaction program included: the initial step of 2 minutes at $50^{\circ} \mathrm{C}$; denaturation at $95^{\circ} \mathrm{C}$ for $10 \mathrm{~min}$, followed by 45 thermal cycles of denaturation $\left(15\right.$ seconds at $\left.95^{\circ} \mathrm{C}\right)$ and elongation $\left(1 \mathrm{~min}\right.$ at $\left.60^{\circ} \mathrm{C}\right)$. The expression values were obtained from the cycle number (Ct value) using the Biosystems analysis software. The threshold cycle $\left(C_{\mathrm{T}}\right)$ values were averaged from each 
reaction, and each gene was normalized to the $18 \mathrm{~S}$ rRNA level. These $\mathrm{Ct}$ values were averaged and the difference between the $18 \mathrm{~S} \mathrm{Ct}$ (Avg) and the gene of interest $\mathrm{Ct}$ (Avg) was calculated (Ct-diff). The relative expression of the gene of interest was analyzed using the $2^{-\Delta \Delta C T}$ method [41]. Quantitative results are expressed as the mean \pm standard deviation (SD). Statistical significance was evaluated by the Student's $t$-test.

\section{Statistical analysis}

All analyses were conducted using SPSS software (version 19.0; SPPS Inc., Chicago, Ill.), and data are presented as mean \pm SD. The association analysis was assessed by using Pearson's chi-square test implemented in SPSS. A P-value $<0.05$ was considered statistically significant for all analyses. Odd ratio and $95 \%$ confidence interval were calculated for the minor allele of each SNP. The Haploview version 4.2 software (hppt://www.borad.mit.edu/mpg/hap loview) was used to analyze the linkage disequilibrium structure, calculating D' to define haplotype block [42] and to estimate haplotype frequencies. Additionally, pairwise linkage disequilibrium (LD) among the SNPs was examined using Lewontin's standardized coefficient D' and LD coefficient r2 [43], and haplotype blocks were defined according to the method of Gabriel et al. [42] in Haploview 4.2 with default settings. Haplotypes within these blocks were estimated using the estimation of maximization algorithm [44]. The associations derived from the comparisons across OSA and NOSA were assessed in terms of odds ratios (OR) both unadjusted and adjusted for age, gender, ethnicity, and obesity with the corresponding 95\% confidence interval (CI).

\section{Results}

The recruitment process of children in this study is shown in Figure 1. As indicated in Figure 1, 970 subjects were recruited, and 362 were excluded from the study because they had chronic medical conditions, such as known genetic syndromes, severe asthma or allergies, or they were receiving chronic medications. A total of 608 children were therefore included, and divided into two groups based on their apnea-hypopnea index (AHI) results in the sleep study: 480 children were controls (NOSA) and 128 children fulfilled the criteria for OSA (OSA) based on AHI. The demographic characteristics and polysomnographic findings of children with OSA and NOSA groups are shown in Table 1, and show markedly similar age, gender, and ethnic distribution indicating that the 2 groups were overall matched for these characteristics. As would be expected based on category attribution criteria, the AHI, apnea index and arousal index were all significantly higher in the OSA group $(\mathrm{P}<0.0001)$. Furthermore, mean $\mathrm{SpO} 2$ levels in OSA were significantly lower than NOSA group $(\mathrm{P}<0.001)$.

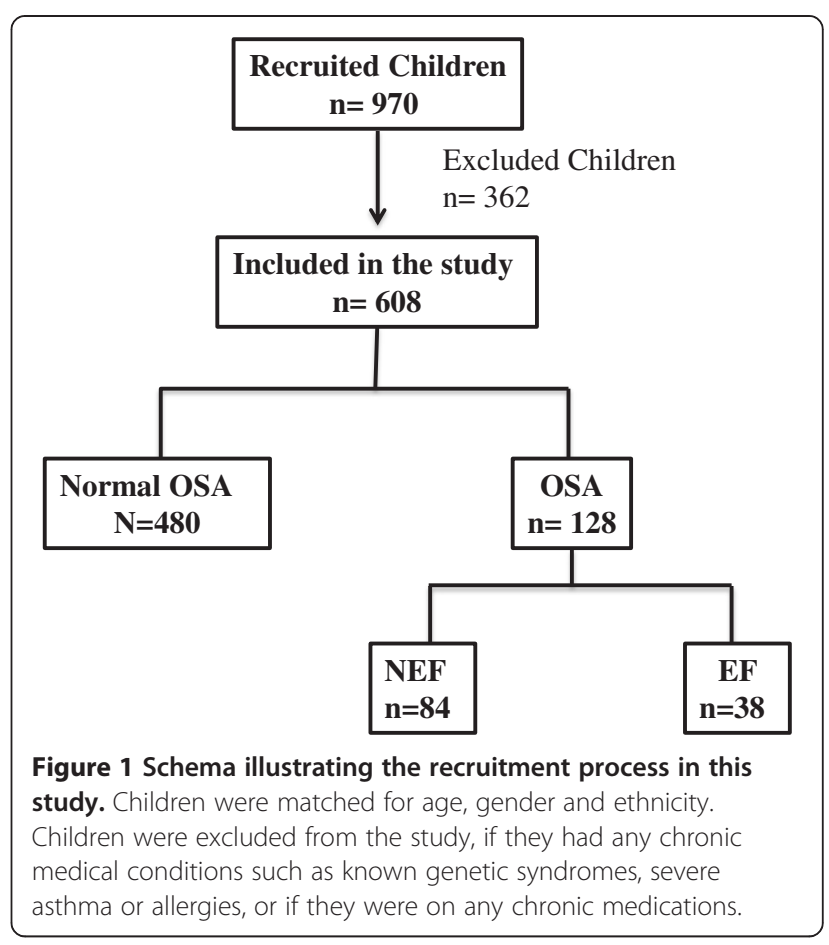

Table 1 Demographic characteristics in children with and without OSA

\begin{tabular}{|c|c|c|c|}
\hline Variables & $\begin{array}{l}\text { NOSA } \\
(n=480)\end{array}$ & $\begin{array}{l}\text { OSA } \\
(n=128)\end{array}$ & $P$-value \\
\hline Age (years) & $7.14 \pm 1.00$ & $7.04 \pm 0.99$ & 0.14 \\
\hline Gender (\% male) & 58.9 & 55.5 & \\
\hline \multicolumn{4}{|l|}{ Ethnicity } \\
\hline White Caucasian \% & 72 & 63.3 & \\
\hline African American \% & 28 & 36.7 & \\
\hline BMI z-score & $0.81 \pm 1.24$ & $1.23 \pm 1.38$ & 0.002 \\
\hline $\mathrm{SBP}(\mathrm{mmHg})$ & $105.46 \pm 10.98$ & $105.86 \pm 8.05$ & 0.44 \\
\hline $\mathrm{DBP}(\mathrm{mmHg})$ & $61.80 \pm 7.65$ & $63.96 \pm 5.53$ & 0.11 \\
\hline Sleep latency (min) & $23.76 \pm 23.99$ & $19.45 \pm 20.71$ & 0.02 \\
\hline REM latency (min) & $151.88 \pm 62.77$ & $155.24 \pm 80.95$ & 0.33 \\
\hline TST (min) & $468.77 \pm 44.90$ & $469.28 \pm 55.29$ & 0.46 \\
\hline Sleep efficiency (\%) & $88.79 \pm 7.89$ & $89.35 \pm 9.80$ & 0.28 \\
\hline Stage 1 (\% TST) & $6.08 \pm 4.61$ & $6.05 \pm 5.85$ & 0.48 \\
\hline Stage 2 (\% TST) & $46.32 \pm 12.73$ & $43.62 \pm 7.93$ & 0.002 \\
\hline Slow wave sleep (\% TST) & $27.67 \pm 9.43$ & $28.91 \pm 8.08$ & 0.07 \\
\hline REM sleep (\%TST) & $20.68 \pm 8.35$ & $20.13 \pm 10.87$ & 0.30 \\
\hline AHI (h-1 TST) & $0.63 \pm 0.49$ & $8.28 \pm 9.27$ & $<0.0001$ \\
\hline Apnea index (h-1 TST) & $0.44 \pm 0.96$ & $2.53 \pm 4.76$ & $<0.0001$ \\
\hline Arousal index (h-1 TST) & $10.06 \pm 7.25$ & $13.37 \pm 7.82$ & $<0.0001$ \\
\hline Mean SaO2 (\%) & $97.21 \pm 4.82$ & $96.24 \pm 2.23$ & 0.0006 \\
\hline Lowest SaO2 (\%) & $92.66 \pm 3.85$ & $86.02 \pm 9.10$ & $<0.0001$ \\
\hline
\end{tabular}


Table 2 Distributions of allele and genotype frequencies of NOS SNPs in children with and without OSA

\begin{tabular}{|c|c|c|c|c|c|c|c|c|c|}
\hline Gene & SNP & Allele & NOSA & & OSA & & P-value & OR & $\mathrm{Cl} 95 \%$ \\
\hline \multirow[t]{43}{*}{ NOS1 } & rs9658535 & $\mathrm{A} / \mathrm{G}$ & $n=477$ & & $\mathrm{n}=128$ & & 0.04 & 0.26 & $0.07-1.06$ \\
\hline & & & $n$ & $\%$ & $n$ & $\%$ & & & \\
\hline & & AA & 421 & 88 & 116 & 91 & & & \\
\hline & & GA & 52 & 11 & 8 & 6 & & & \\
\hline & & GG & 4 & 1 & 4 & 3 & & & \\
\hline & & Allele A & 894 & 94 & 240 & 94 & & & \\
\hline & & Allele G & 60 & 6 & 16 & 6 & & & \\
\hline & rs7960451 & $\mathrm{C} / \mathrm{T}$ & $n=480$ & & $n=128$ & & 0.02 & 0.21 & $0.05-0.78$ \\
\hline & & & $n$ & $\%$ & $n$ & $\%$ & & & \\
\hline & & CC & 417 & 87 & 112 & 87 & & & \\
\hline & & $\mathrm{TC}$ & 59 & 12 & 11 & 9 & & & \\
\hline & & $\pi$ & 4 & 1 & 5 & 4 & & & \\
\hline & & Allele C & 893 & 93 & 235 & 92 & & & \\
\hline & & Allele T & 67 & 7 & 21 & 8 & & & \\
\hline & rs4767524 & $C / G$ & $n=478$ & & $n=128$ & & 0.04 & 0.71 & $0.43-1.15$ \\
\hline & & & $n$ & $\%$ & $n$ & $\%$ & & & \\
\hline & & CC & 160 & 33 & 52 & 41 & & & \\
\hline & & GC & 242 & 51 & 49 & 38 & & & \\
\hline & & GG & 76 & 16 & 27 & 21 & & & \\
\hline & & Allele C & 562 & 59 & 153 & 60 & & & \\
\hline & & Allele G & 394 & 41 & 103 & 40 & & & \\
\hline & rs 2293050 & $A / G$ & $n=478$ & & $n=128$ & & 0.0002 & 1.59 & $1.04-2.43$ \\
\hline & & & $n$ & $\%$ & $n$ & $\%$ & & & \\
\hline & & AA & 82 & 17 & 13 & 10 & & & \\
\hline & & $A G$ & 208 & 44 & 78 & 61 & & & \\
\hline & & GG & 188 & 39 & 37 & 29 & & & \\
\hline & & Allele A & 372 & 39 & 104 & 41 & & & \\
\hline & & Allele G & 584 & 61 & 152 & 59 & & & \\
\hline & rs 10744891 & $\mathrm{G} / \mathrm{T}$ & $n=465$ & & $n=121$ & & 0.004 & 1.72 & $0.90-3.28$ \\
\hline & & & $n$ & $\%$ & $n$ & $\%$ & & & \\
\hline & & GG & 185 & 40 & 35 & 29 & & & \\
\hline & & $\mathrm{TG}$ & 206 & 44 & 74 & 61 & & & \\
\hline & & $\pi$ & 74 & 16 & 12 & 10 & & & \\
\hline & & Allele G & 576 & 62 & 144 & 60 & & & \\
\hline & & Allele T & 354 & 38 & 98 & 40 & & & \\
\hline & rs9658354 & $\mathrm{A} / \mathrm{T}$ & $n=478$ & & $n=126$ & & 0.001 & 1.74 & $1.13-2.68$ \\
\hline & & & $n$ & $\%$ & $n$ & $\%$ & & & \\
\hline & & $\mathrm{AA}$ & 80 & 17 & 13 & 10 & & & \\
\hline & & AT & 211 & 44 & 79 & 63 & & & \\
\hline & & $\pi$ & 187 & 39 & 34 & 27 & & & \\
\hline & & Allele A & 371 & 39 & 105 & 42 & & & \\
\hline & & Allele T & 585 & 61 & 147 & 58 & & & \\
\hline & rs2139733 & $\mathrm{A} / \mathrm{T}$ & $n=478$ & & $n=128$ & & 0.002 & 1.65 & $1.08-2.52$ \\
\hline & & & $n$ & $\%$ & $n$ & $\%$ & & & \\
\hline
\end{tabular}


Table 2 Distributions of allele and genotype frequencies of NOS SNPs in children with and without OSA (Continued)

\begin{tabular}{|c|c|c|c|c|c|c|c|c|}
\hline & $\mathrm{AA}$ & 77 & 16 & 13 & 10 & & & \\
\hline & AT & 209 & 44 & 78 & 61 & & & \\
\hline & $\pi$ & 192 & 40 & 37 & 29 & & & \\
\hline & Allele A & 363 & 38 & 104 & 41 & & & \\
\hline & Allele T & 593 & 62 & 152 & 59 & & & \\
\hline \multirow[t]{7}{*}{ rs1520810 } & $\mathrm{A} / \mathrm{T}$ & $n=478$ & & $n=127$ & & 0.03 & 0.86 & $0.38-1.94$ \\
\hline & & $n$ & $\%$ & $n$ & $\%$ & & & \\
\hline & $\mathrm{AA}$ & 263 & 55 & 85 & 67 & & & \\
\hline & TA & 189 & 40 & 34 & 27 & & & \\
\hline & $\pi$ & 26 & 5 & 8 & 6 & & & \\
\hline & Allele A & 715 & 75 & 204 & 80 & & & \\
\hline & Allele T & 241 & 25 & 50 & 20 & & & \\
\hline \multirow[t]{7}{*}{ rs471871 } & $\mathrm{A} / \mathrm{T}$ & $n=478$ & & $n=127$ & & 0.01 & 0.55 & $0.37-0.82$ \\
\hline & & $n$ & $\%$ & $n$ & $\%$ & & & \\
\hline & $\mathrm{AA}$ & 51 & 11 & 13 & 10 & & & \\
\hline & AT & 212 & 44 & 38 & 30 & & & \\
\hline & $\pi T$ & 215 & 45 & 76 & 60 & & & \\
\hline & Allele A & 314 & 33 & 64 & 25 & & & \\
\hline & Allele T & 642 & 67 & 190 & 75 & & & \\
\hline \multirow[t]{7}{*}{ rs528558 } & $\mathrm{A} / \mathrm{G}$ & $n=479$ & & $n=128$ & & 0.03 & 0.61 & $0.41-0.92$ \\
\hline & & $\mathrm{n}$ & $\%$ & $n$ & $\%$ & & & \\
\hline & $\mathrm{AA}$ & 26 & 5 & 8 & 6 & & & \\
\hline & $A G$ & 191 & 40 & 35 & 27 & & & \\
\hline & GG & 262 & 55 & 85 & 66 & & & \\
\hline & Allele A & 243 & 25 & 51 & 20 & & & \\
\hline & Allele G & 715 & 75 & 205 & 80 & & & \\
\hline \multirow[t]{7}{*}{ rs816296 } & $\mathrm{A} / \mathrm{C}$ & $n=478$ & & $n=127$ & & 0.04 & 0.58 & $0.38-0.89$ \\
\hline & & $\mathrm{n}$ & $\%$ & $n$ & $\%$ & & & \\
\hline & $\mathrm{AA}$ & 24 & 5 & 4 & 3 & & & \\
\hline & $A C$ & 174 & 36 & 33 & 26 & & & \\
\hline & CC & 280 & 59 & 90 & 71 & & & \\
\hline & Allele A & 222 & 23 & 41 & 16 & & & \\
\hline & Allele C & 734 & 77 & 213 & 84 & & & \\
\hline \multirow[t]{7}{*}{ rs579604 } & $\mathrm{C} / \mathrm{T}$ & $n=479$ & & $\mathrm{n}=128$ & & 0.04 & N/A & N/A \\
\hline & & $n$ & $\%$ & $n$ & $\%$ & & & \\
\hline & CC & 310 & 65 & 96 & 75 & & & \\
\hline & $\mathrm{TC}$ & 158 & 33 & 32 & 25 & & & \\
\hline & $\pi$ & 11 & 2 & 0 & 0 & & & \\
\hline & Allele C & 778 & 81 & 224 & 88 & & & \\
\hline & Allele T & 180 & 19 & 32 & 12 & & & \\
\hline \multirow[t]{5}{*}{ rs1552227 } & $\mathrm{C} / \mathrm{T}$ & $\mathrm{n}=479$ & & $n=128$ & & 0.02 & 0.47 & $0.22-0.97$ \\
\hline & & $n$ & $\%$ & $n$ & $\%$ & & & \\
\hline & CC & 294 & 61 & 63 & 49 & & & \\
\hline & TC & 163 & 34 & 53 & 42 & & & \\
\hline & $\pi$ & 22 & 5 & 12 & 9 & & & \\
\hline
\end{tabular}


Table 2 Distributions of allele and genotype frequencies of NOS SNPs in children with and without OSA (Continued)

\begin{tabular}{|c|c|c|c|c|c|c|c|c|c|}
\hline & & Allele C & 751 & 78 & 179 & 70 & & & \\
\hline & & Allele T & 207 & 22 & 77 & 30 & & & \\
\hline & rs17509231 & $\mathrm{C} / \mathrm{T}$ & $\mathrm{n}=478$ & & $n=128$ & & 0.02 & 0.40 & $0.07-2.41$ \\
\hline & & & $n$ & $\%$ & $n$ & $\%$ & & & \\
\hline & & CC & 395 & 83 & 92 & 72 & & & \\
\hline & & $\mathrm{TC}$ & 80 & 17 & 34 & 26 & & & \\
\hline & & $\pi$ & 3 & 0 & 2 & 2 & & & \\
\hline & & Allele C & 870 & 91 & 218 & 85 & & & \\
\hline & & Allele T & 86 & 9 & 38 & 15 & & & \\
\hline & rs3782221 & $\mathrm{A} / \mathrm{G}$ & $n=477$ & & $n=128$ & & 0.02 & 0.61 & $0.41-0.90$ \\
\hline & & & $n$ & $\%$ & $n$ & $\%$ & & & \\
\hline & & $\mathrm{AA}$ & 36 & 7 & 4 & 3 & & & \\
\hline & & $A G$ & 213 & 45 & 47 & 37 & & & \\
\hline & & GG & 228 & 48 & 77 & 60 & & & \\
\hline & & Allele A & 285 & 30 & 55 & 21 & & & \\
\hline & & Allele G & 669 & 70 & 201 & 79 & & & \\
\hline \multirow[t]{7}{*}{ NOS3 } & rs1800780 & $\mathrm{A} / \mathrm{G}$ & $n=47 c$ & & $n=126$ & & 0.05 & 0.71 & $0.47-1.09$ \\
\hline & & & $n$ & $\%$ & $n$ & $\%$ & & & \\
\hline & & $\mathrm{AA}$ & 103 & 22 & 16 & 13 & & & \\
\hline & & $A G$ & 240 & 51 & 67 & 53 & & & \\
\hline & & GG & 127 & 27 & 43 & 34 & & & \\
\hline & & Allele A & 446 & 47 & 99 & 39 & & & \\
\hline & & Allele G & 494 & 53 & 153 & 61 & & & \\
\hline
\end{tabular}

Notably, we did not find any significant differences in systemic blood pressure among the 2 groups.

From a total of 381 SNPs assayed for the 3 NOS $-1,-2$ and-3 genes, 15 SNPs in the NOS1 gene and 1 SNP for NOS3 gene exhibited statistically significant differences in their frequencies among children with OSA and their matched controls, even after correction for multiple comparisons (Table 2). Linkage disequilibrium (LD) analysis of the 15 SNPs in the NOS1 gene was assessed for both OSA and NOSA subjects. In NOSA subjects, two haplotype blocks emerged, and are outlined in black triangular regions in Figure 2 (Panel A). In OSA subjects, the haplotype showed the presence of 2 blocks as well (Figure 2, Panel B). The haplotype of these blocks and their frequencies in OSA and NOSA are shown in Figure 3, Panels A and B, respectively. Taken together, the patterns of LD and haplotype frequencies differed between OSA and NOSA, suggesting that some of these SNPs may contribute to OSA risk.

From a total of 155 SNPs for the three EDN-1,-2 and3 genes and their associated EDN receptors (EDNRA and $E D N R B$ ), there were 4 SNPs in EDN1, and 1 SNP in both of EDN2 and EDN3, in which allelic frequencies were significantly altered in children with OSA (Table 3). No differences emerged for $E D N$ receptor (EDNRA, EDNRB)
SNPs. The list and the summary of the significant SNPs in both NOS and EDN genes such as location of these SNPs, percentage of minor allele frequency (\%MAF) are shown in Additional file 1: Table S1.

Next, we divided OSA subjects into 2 subgroups based on their individual Tmax values, when such values were available: OSA with normal endothelial function (OSA$\mathrm{NEF}$ ), and OSA with endothelial dysfunction (OSA-ED). As shown in Figure 4, Tmax values were significantly higher in the 6 OSA-ED subjects compared to 17 subjects with OSA-NEF $(\mathrm{P}<0.002)$.

In addition, we quantified the mRNA expression of the EDN1 gene in 18 matched subjects, 9 with NOSA and 9 with OSA using qRT-PCR. As shown in Figure 5, EDN1 was significantly increased in children with OSA compared to NOSA ( $P$-value 0.0005).

\section{Discussion}

In this study, we report on the allelic frequencies associations of NOS and EDN gene families in children with and without OSA. The frequency of specific NOS1 and EDN1 SNPs was significantly associated with the presence of OSA, while the frequencies of all other SNPs tested for the NOS and EDN genes did not show any 
(A)

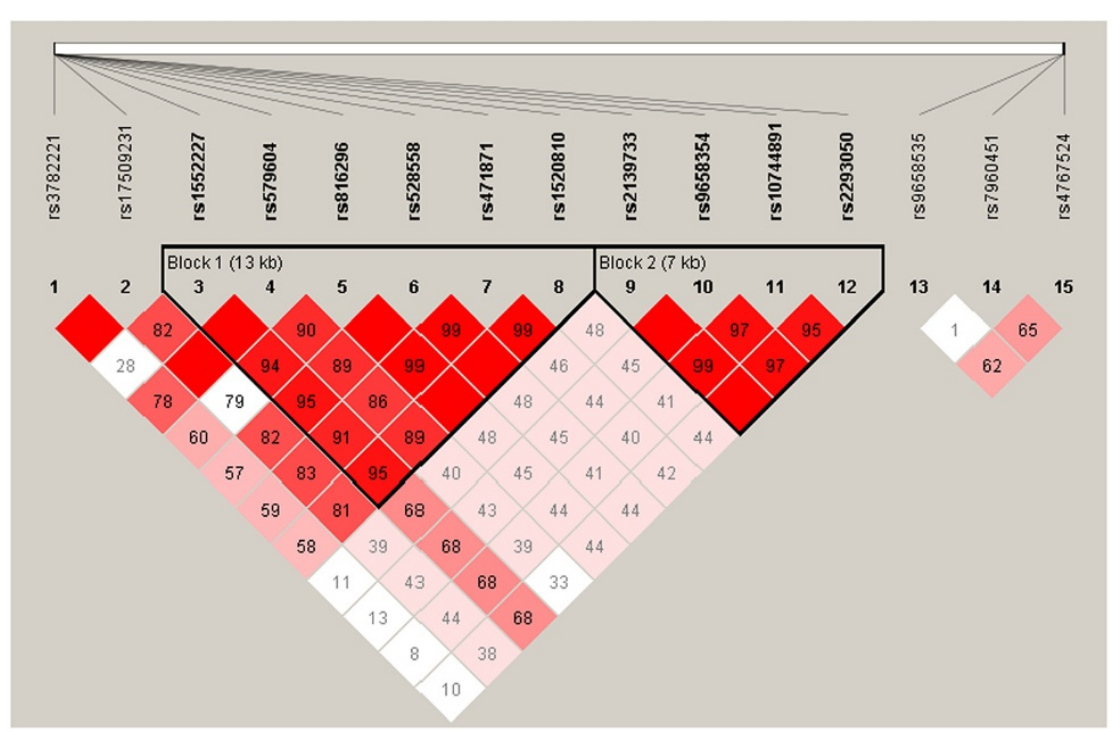

(B)

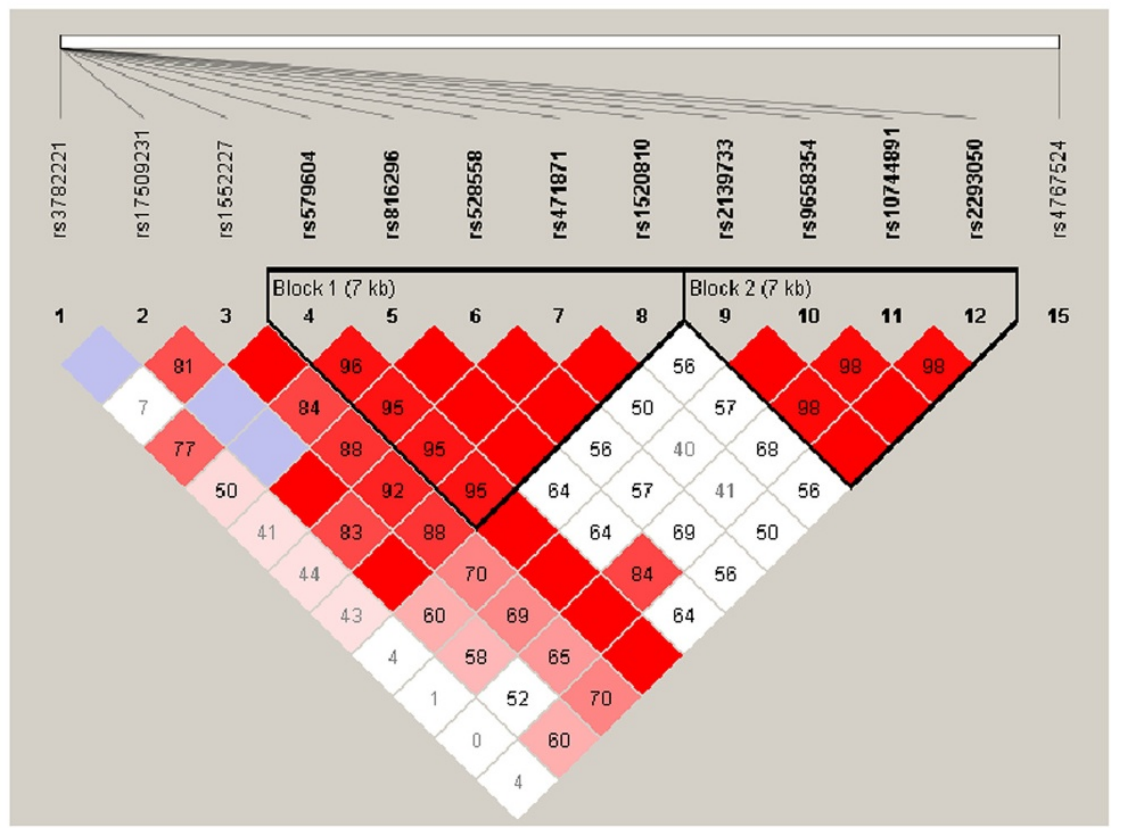

Figure 2 Pairwise linkage disequilibrium (LD) structure and 15 SNPs of the NOS1 gene. Panel (A) represents children without OSA (NOSA), and Panel (B) represents children with OSA (OSA). The plot was generated using Haploview 4.2 with $D^{\prime}$ Color Scheme $\left(D^{\prime}=0, D^{\prime}<1\right.$ and $D^{\prime}=1$ shown by white, shades of pink and red (respectively) and pairwise $r^{2}$ values shown in diamonds. The value within each diamond represents the pair-wise LD (correlation, measured as D') between the two SNPs defined by the top left and the top right of the diamond. Solid lines represent SNPs that were used in the haplotype analysis, and are part of the haplotype from SNP block whereas dashed lines represent SNPs that were used in the analysis, but were not part of the haplotype.

significant differences between OSA and NOSA. In addition, a subset of the children with OSA showed evidence of endothelial dysfunction even though they were asymptomatic and identified through community-based systematic surveys, thereby confirming previous findings in clinical cohorts on the adverse effect of OSA on endothelial function. Furthermore, in a small subset of children for whom RNA samples were available from peripheral blood monocytes, EDN1 gene expression was elevated in children with OSA compared to controls.

Before we discuss the potential significance of our findings, some methodological issues deserve comment, in particular subject selection considerations and genetic variances. First, we excluded any child with known diabetes, hypertension, or any other chronic disease condition. This approach could therefore have artificially 
(A)

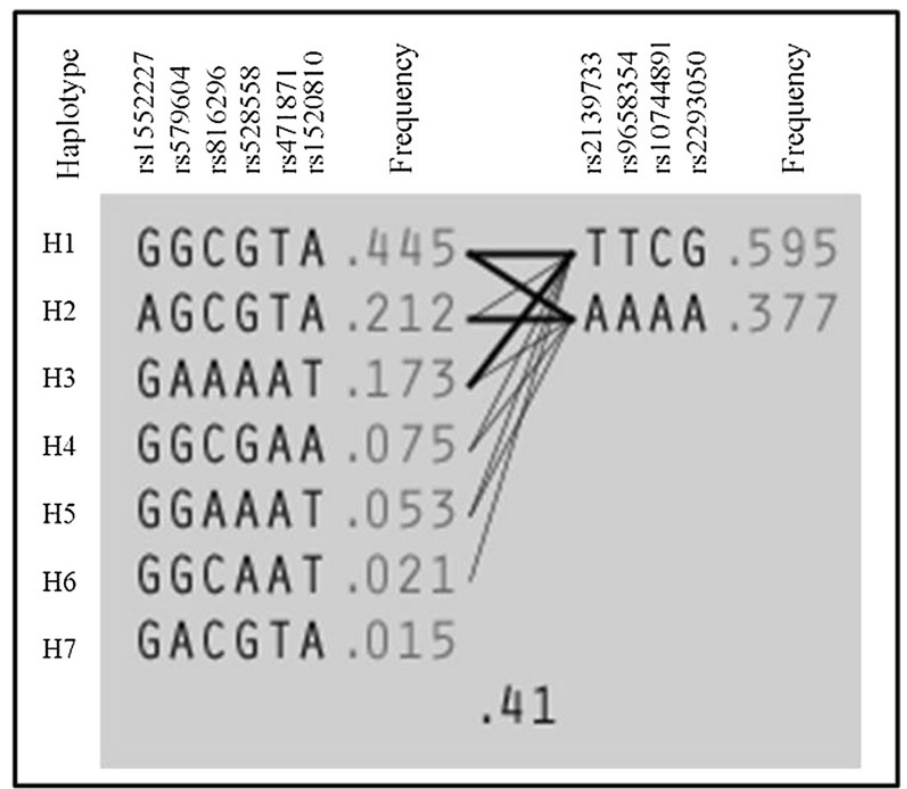

(B)

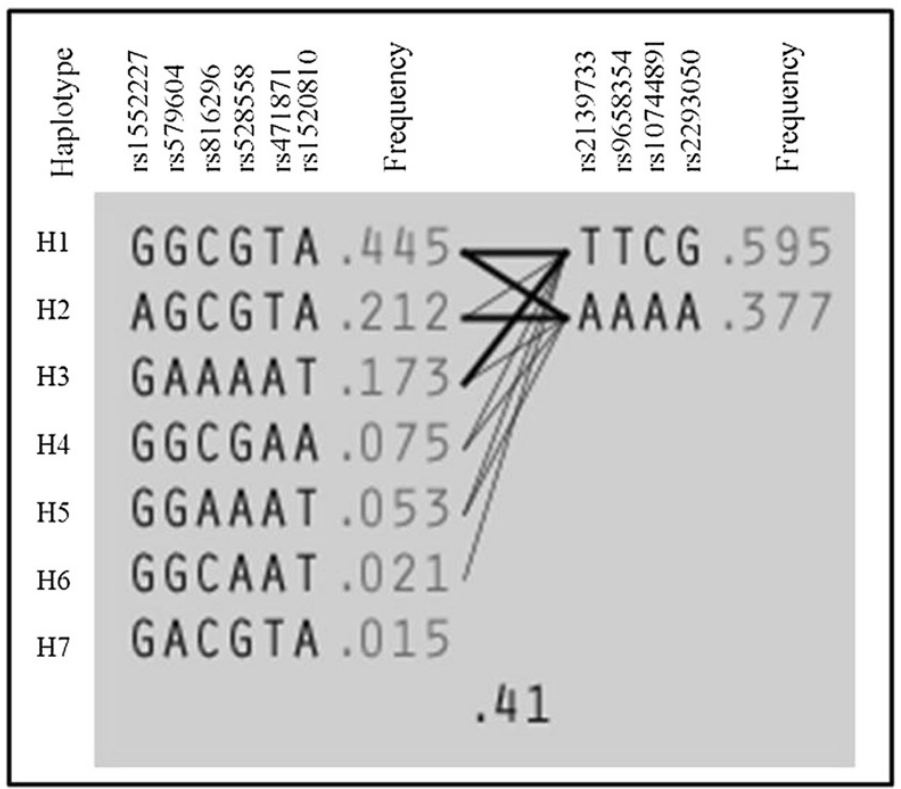

Figure 3 Haplotype frequencies in children with and without OSA. Panel (A) represents haplotype for children without OSA (NOSA), and Panel (B) represents haplotype for children with OSA (OSA).

reduced the magnitude of the association of any given NOS of EDN allelic variant with OSA. Second, we narrowed the age range of the current cohort such as to minimize as much as possible any confounding factors that might be operational across a wide age range in OSA. Thirdly, closely matched control children are included which should minimize the effect of modifying factors that could be involved in the process of subject selection. In addition, the use of the laser Doppler technique for assessment of vascular responses following cuff-induced arterial occlusion not only permits reproducible determination of the kinetics of post-ischemic reperfusion, but also serves as an accurate reporter of nitric oxide-mediated physiological recruitment of the microvasculature $[37,45]$. In this context, we also excluded children with a variety of diagnoses that can be associated with endothelial dysfunction [46]. The two important limitations of this study include the relatively small size of the cohort of children studied which could hamper statistical power, and the absence of endothelin 
Table 3 Distributions of allele and genotype frequencies of EDN SNPs in children with and without OSA

\begin{tabular}{|c|c|c|c|c|c|c|c|c|c|}
\hline \multirow{2}{*}{$\frac{\text { Gene }}{\text { EDN1 }}$} & \multirow{2}{*}{$\begin{array}{l}\text { SNP } \\
\text { rs1014505 }\end{array}$} & \multirow[t]{2}{*}{ Allele } & \multicolumn{2}{|c|}{ NOSA } & \multicolumn{2}{|l|}{ OSA } & \multirow{2}{*}{$\begin{array}{l}\text { P-value } \\
<0.001\end{array}$} & \multirow{2}{*}{$\frac{\text { OR }}{1.28}$} & \multirow{2}{*}{$\begin{array}{l}\mathrm{Cl} 95 \% \\
0.85-1.92\end{array}$} \\
\hline & & & $\mathrm{n}=47$ & & $\mathrm{n}=12$ & & & & \\
\hline & & $C / G$ & $\mathrm{n}$ & $\%$ & $n$ & $\%$ & & & \\
\hline & & CC & 62 & 13 & 36 & 29 & & & \\
\hline & & CG & 215 & 45 & 45 & 35 & & & \\
\hline & & GG & 201 & 42 & 46 & 36 & & & \\
\hline & & Allele C & 339 & 35 & 117 & 46 & & & \\
\hline & & Allele G & 617 & 65 & 137 & 54 & & & \\
\hline & rs2070698 & $\mathrm{C} / \mathrm{T}$ & $\mathrm{n}=48$ & & $\mathrm{n}=12$ & & 0.04 & 1.73 & $1.07-2.79$ \\
\hline & & & $\mathrm{n}$ & $\%$ & $n$ & $\%$ & & & \\
\hline & & CC & 102 & 21 & 37 & 29 & & & \\
\hline & & $C T$ & 236 & 49 & 66 & 52 & & & \\
\hline & & $\pi$ & 142 & 30 & 25 & 19 & & & \\
\hline & & Allele C & 440 & 46 & 140 & 55 & & & \\
\hline & & Allele T & 520 & 54 & 116 & 45 & & & \\
\hline & rs2248580 & & $\mathrm{n}=47$ & & $\mathrm{n}=12$ & & 0.02 & 1.07 & $0.72-1.59$ \\
\hline & & $\mathrm{A} / \mathrm{C}$ & $n$ & $\%$ & $n$ & $\%$ & & & \\
\hline & & $A A$ & 60 & 12 & 28 & 22 & & & \\
\hline & & $A C$ & 208 & 44 & 46 & 36 & & & \\
\hline & & CC & 210 & 44 & 54 & 42 & & & \\
\hline & & Allele A & 328 & 34 & 102 & 40 & & & \\
\hline & & Allele C & 628 & 66 & 154 & 60 & & & \\
\hline & rs2070699 & $\mathrm{G} / \mathrm{T}$ & $\mathrm{n}=47$ & & $\mathrm{n}=12$ & & 0.002 & 0.42 & $0.25-0.69$ \\
\hline & & & $n$ & $\%$ & $n$ & $\%$ & & & \\
\hline & & GG & 213 & 45 & 55 & 43 & & & \\
\hline & & $\mathrm{TG}$ & 216 & 45 & 45 & 35 & & & \\
\hline & & $\pi$ & 50 & 10 & 28 & 22 & & & \\
\hline & & Allele G & 642 & 67 & 155 & 61 & & & \\
\hline & & Allele T & 316 & 33 & 101 & 39 & & & \\
\hline \multirow[t]{7}{*}{ EDN2 } & rs11210273 & $\mathrm{C} / \mathrm{T}$ & $\mathrm{n}=47$ & & $n=12$ & & 0.02 & NA & NA \\
\hline & & & $n$ & $\%$ & $n$ & $\%$ & & & \\
\hline & & CC & 411 & 86 & 105 & 82 & & & \\
\hline & & $\mathrm{TC}$ & 67 & 14 & 21 & 16 & & & \\
\hline & & $\pi$ & 0 & 0 & 2 & 2 & & & \\
\hline & & Allele C & 889 & 93 & 231 & 90 & & & \\
\hline & & Allele T & 67 & 7 & 25 & 10 & & & \\
\hline \multirow[t]{7}{*}{ EDN3 } & rs6064764 & $\mathrm{C} / \mathrm{T}$ & $\mathrm{n}=47$ & & $n=12$ & & 0.02 & 0.90 & $0.60-1.34$ \\
\hline & & & $n$ & $\%$ & $n$ & $\%$ & & & \\
\hline & & CC & 27 & 6 & 15 & 12 & & & \\
\hline & & $C T$ & 174 & 36 & 35 & 27 & & & \\
\hline & & $\pi$ & 278 & 58 & 77 & 61 & & & \\
\hline & & Allele C & 228 & 24 & 65 & 26 & & & \\
\hline & & Allele T & 730 & 76 & 189 & 74 & & & \\
\hline
\end{tabular}




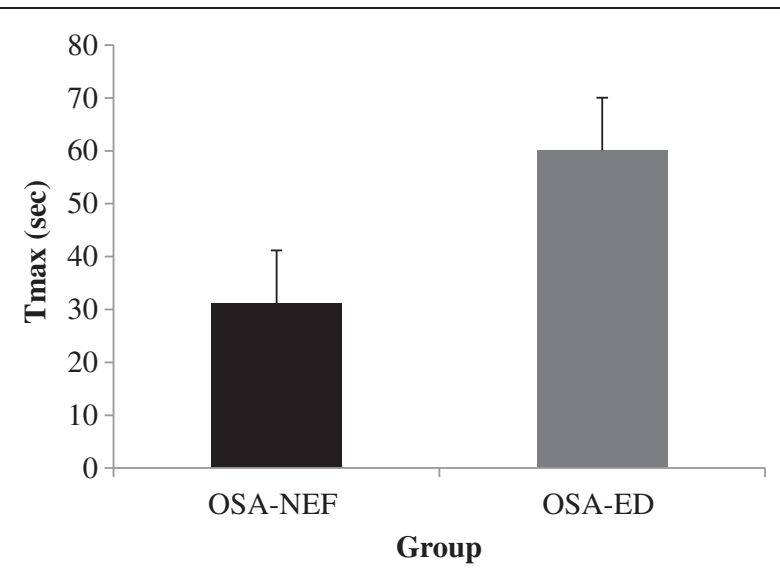

Figure 4 Individual Tmax values in children with OSA and normal endothelial function (OSA-NEF), and children with OSA with endothelial dysfunction (OSA-ED).

plasma level measurements in blood cells for the genes of interest. Although highly desirable, the latter were not possible due to limitations in the amount of blood samples. However, inclusion of the present preliminary findings on endothelial function are intent on further illustrating future directions that will need to encompass specific gene variants to not only the presence or absence of a disorder, i.e., OSA, but also to the presence or absence of a consequence of the disorder, i.e., endothelial dysfunction.

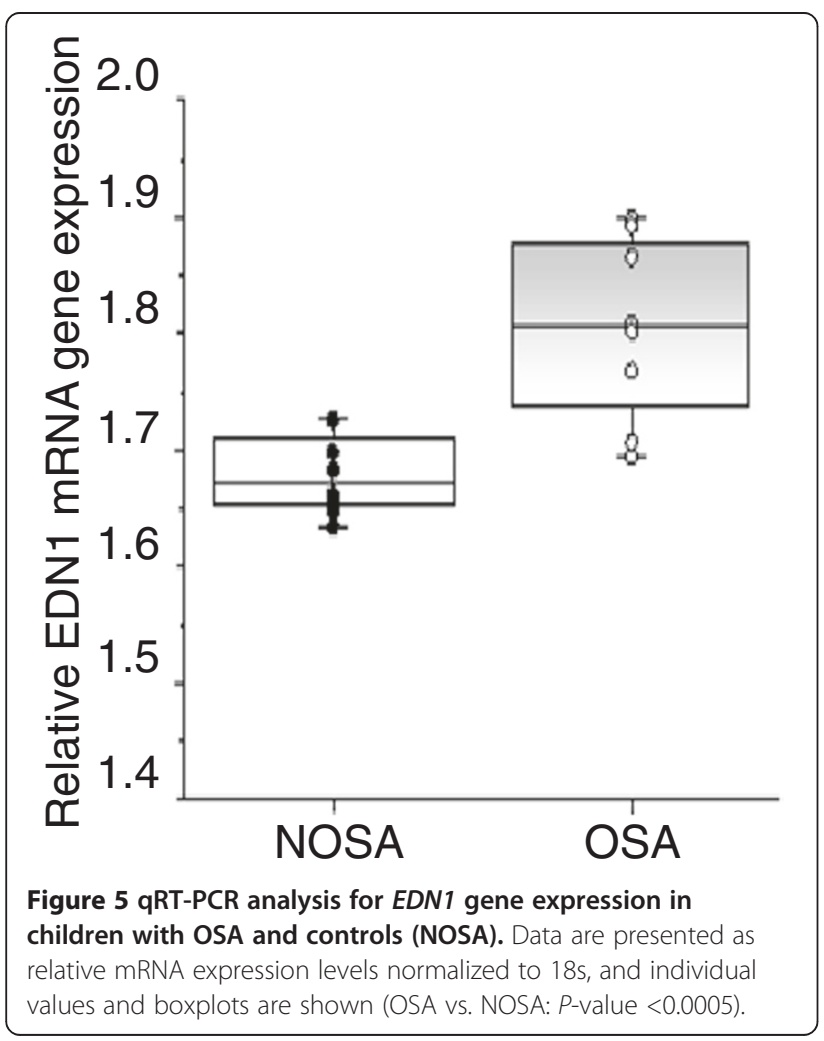

We and others have previously shown significant associations between specific gene candidate variances and OSAassociated phenotypes, and this study adds incremental information to potentially significant contributions of $E D N$ and NOS gene polymorphisms to this issue [8,47-51]. However, the overall modulatory effects of these polymorphisms to the clinical phenotype of pediatric OSA will have to await more extensive studies involving much larger cohorts. Accordingly, we opted not to implement additional valuable analytical methodologies to derive what we perceive as somewhat premature inferential conclusions from such methods [52,53].

OSA is a multi-factorial and highly prevalent disorder in which both genetic and environmental factors may be involved $[54,55]$. The role of specific genes that influence the development of OSA is unclear. A precise genetic foundation of OSA has been thus far difficult to identify, because it is still unknown whether some of the putative candidate genes for OSA are directly causal to the expression of the disorder or whether their role in OSA is mediated through other intermediate genes. Similarly, the phenotypic expression of OSA and its consequences is most likely determined by multiple genetic and environmental factors and their interactions. Some of the factors assumed to operate as intrinsic genetic determinants of susceptibility [56-58] have been shown to include inflammatory pathways, lipid membrane transport, and growth factors [58]. Additional external factors that have yet to be corroborated in clinical pediatric cohorts include lifestyle components, such as physical activity, and dietary habits. Previous studies have reported that several single nucleotide polymorphisms might be involved in the pathogenesis of OSA both in adult and children, such as serotonin transporter $(5-H T T)$ [59], TNF- $\alpha[49,60]$, fatty acid binding protein $4[48,61]$, macrophage migration inhibitory factor [47], NADPH oxidase p22 sub-unit [8,50], and angiotensin I converting enzyme (ACE) $[62,63]$.

In this study, we used 536 SNPs from different genes and pathways to study the association of their allelic frequencies in children with OSA. Here, we show in a total of 209 SNPs assayed with NOS1 gene, we identified 15 significantly SNPs those allelic frequencies were associated in children with OSA. To the best of our knowledge, no studies were conducted on genetic variance of NOS genes in children with OSA. However, several studies have been reported in human using NOS SNPs. For example, several polymorphisms located in NOS1, NOS2, and NOS3 genes have been identified; some of these polymorphic sites could be responsible for variations in the genetic control of plasma NOS levels, which would be a useful tool for studying the relationship between NOS and diseases including asthma [64,65], depressive disorder [66], Parkinson's disease [67], diabetic nephropathy [68], and stroke [69]. 
The endothelin system consists of G protein-coupled endothelin receptors $(E D N R)$ that are activated by endothelin $(E D N)$ signaling peptides. Specific interactions between the three different endothelin-subtypes $(E D N-1,-2,-3)$ and the two human endothelin receptors (EDNRA, $E D N R B)$ are known [70]. Endothelin-1 (EDN 1), the most potent vasoconstrictor of the human organism, uses mainly the EDNRA as a signal transduction pathway. Our results show different allelic frequencies of $E D N$ polymorphisms between OSA subjects and controls. For example, of 155 SNPs for the three $E D N-1,-2$ and-3 genes and their associated $E D N$ receptors (EDNRA and EDNRB), there were 4 SNPs in EDN1, and 1 SNP in both of $E D N 2$ and $E D N 3$, in which allelic frequencies were significantly altered in children with OSA. We are only aware of a single published report on genetic polymorphisms in endothelin-receptor-subtype-a-gene as a susceptibility factor for adult OSA [32]. These investigators identified 4 candidate SNPs out of 100 in ENDRA in patients with OSA, but did not ascertain the significance of their findings by haplotype analysis. Endothelin-1 (EDN1) is an intercellular signaling molecule expressed in many different organ systems and tissues. Although $E D N 1$ is best known as a potent vasoconstrictor, EDN1 also plays important roles in the kidney, nervous system, and in the heart [71]. Furthermore, genetic polymorphisms in the EDN1 promoter region have been linked to an increased incidence of left ventricular hypertrophy [72], and asthma [73], a known consequence of OSA in children [74]. The increased expression of EDN1 among children with OSA in the present study would further suggest that genotype-phenotype interactions may indeed be present in pediatric OSA and its cardiovascular morbidities. Indeed, several lines of evidence derived from both clinical studies and animal models have shown that increases in circulating EDN1 in OSA [75-77].

\section{Conclusion}

In conclusion, our results suggest that the NOS1 and $E D N 1$ genes may confer an increased risk for the presence of OSA or downstream morbidity. The susceptibility to OSA is a multifactorial process and may result from genetic variants in many genes on different chromosomes. Also, genetic epidemiological studies of biological phenotypes involved in the same pathway can provide relevant information, and can contribute to unravel the mechanisms underlying complex diseases such as OSA. More specifically, the changes in EDN1 gene expression particularly when combined with differences in the distribution of EDN1 polymorphisms, suggest these specific SNPs influence the genetic predisposition to OSA. Thus, analysis of the currently identified EDN1 polymorphism may be useful in the assessment of risk for OSA in a high risk population, such as those children who manifest snoring or have enlarged tonsils and adenoids. Further studies should be carried out to confirm the association reported herein in expanded pediatric cohorts, and tentatively include protein and gene expression levels to enable deciphering the importance and functionality of these genetic factors.

\section{Additional file}

Additional file 1: Table S1. List of single nucleotide polymorphisms (SNPS) of NOS and EDN genes.

Competing interests

The authors declare that they have no competing interests.

\section{Authors' contributions}

SC performed data analysis, and GRT-PCR validation, DG provided the conceptual design of the project, participated in the data analysis and editing final version of the manuscript, L K-G participated in data analysis and sleep studies, RB participated in clinical data, AAK participated in data analysis and haploview, YW reviewed data, WS participated in general discussion and review data, and AK carried data analysis, overall the project and SNPs analysis, writing and editing manuscript. All authors read and approved the final manuscript.

\section{Funding sources}

DG is supported by National Institutes of Health grants HL-065270 and HL-086662. SC is the recipient of the Royal Golden Jubilee Ph. D. Program Award from the Thailand Research Fund (PHD/0138/2552).

\section{Author details}

${ }^{1}$ Department of Pediatrics, Comer Children's Hospital, Pritzker School of Medicine, Biological Sciences Division, The University of Chicago, 900 E, 57th Street, KCBD, 4112, Chicago, IL 60637, USA. ²Department of Biochemistry, Faculty of Medicine, Srinakharinwirot University, Sukhumvit 23, Bangkok 10110, Thailand

Received: 27 May 2013 Accepted: 29 August 2013 Published: 6 September 2013

\section{References}

1. Punjabi NM: The epidemiology of adult obstructive sleep apnea. Proc Am Thorac Soc 2008, 5(2):136-143.

2. Lumeng JC, Chervin RD: Epidemiology of pediatric obstructive sleep apnea. Proc Am Thorac Soc 2008, 5(2):242-252.

3. Vlahandonis A, Walter LM, Horne RS: Does treatment of SDB in children improve cardiovascular outcome? Sleep medicine reviews 2013, 17(1):75-85.

4. Gottlieb DJ, Yenokyan G, Newman AB, O'Connor GT, Punjabi NM, Quan SF, Redline S, Resnick HE, Tong EK, Diener-West M, et al: Prospective study of obstructive sleep apnea and incident coronary heart disease and heart failure: the sleep heart health study. Circulation 2010, 122(4):352-360.

5. Gozal D: Morbidity of obstructive sleep apnea in children: facts and theory. Sleep Breath 2001, 5(1):35-42.

6. Gozal D, Capdevila OS, Kheirandish-Gozal L: Metabolic alterations and systemic inflammation in obstructive sleep apnea among nonobese and obese prepubertal children. Am J Respir Crit Care Med 2008, 177(10):1142-1149

7. Gozal D, Kheirandish-Gozal L: Cardiovascular morbidity in obstructive sleep apnea: oxidative stress, inflammation, and much more. Am J Respir Crit Care Med 2008, 177(4):369-375.

8. Gozal D, Khalyfa A, Capdevila OS, Kheirandish-Gozal L, Khalyfa AA, Kim J: Cognitive function in prepubertal children with obstructive sleep apnea: a modifying role for NADPH oxidase p22 subunit gene polymorphisms? Antioxid Redox Signal 2012, 16(2):171-177.

9. Lurie A: Cardiovascular disorders associated with obstructive sleep apnea. Advances in cardiology 2011, 46:197-266. 
10. Kohli P, Balachandran JS, Malhotra A: Obstructive sleep apnea and the risk for cardiovascular disease. Current atherosclerosis reports 2011, 13(2):138-146

11. Sánchez-de-la-Torre M: Obstructive sleep apnoea and cardiovascular disease. Lancet Respir Med 2013, 1(1):61-62.

12. Somers VK, White DP, Amin R, Abraham WT, Costa F, Culebras A, Daniels S, Floras JS, Hunt CE, Olson L, et al: Sleep apnea and cardiovascular disease: an American heart association/american college Of cardiology foundation scientific statement from the American heart association council for high blood pressure research professional education committee, council on clinical cardiology, stroke council, and council on cardiovascular nursing. In collaboration with the national heart, lung, and blood institute national center on sleep disorders research (national institutes of health). Circulation 2008, 118(10):1080-1111.

13. Kato M, Roberts-Thomson P, Phillips BG, Haynes WG, Winnicki M, Accurso V, Somers VK: Impairment of endothelium-dependent vasodilation of resistance vessels in patients with obstructive sleep apnea. Circulation 2000, 102(21):2607-2610.

14. Gozal D, Kheirandish-Gozal L, Serpero LD, Sans Capdevila O, Dayyat E: Obstructive sleep apnea and endothelial function in school-aged nonobese children: effect of adenotonsillectomy. Circulation 2007, 116(20):2307-2314.

15. Bhattacharjee R, Kim J, Alotaibi WH, Kheirandish-Gozal L, Capdevila OS, Gozal D: Endothelial dysfunction in children without hypertension: potential contributions of obesity and obstructive sleep apnea. Chest 2012, 141(3):682-691.

16. Alvarez R, Gonzalez P, Batalla A, Reguero JR, Iglesias-Cubero G, Hevia S, Cortina A, Merino E, Gonzalez I, Alvarez V, et al: Association between the NOS3 (-786 T/C) and the ACE (I/D) DNA genotypes and early coronary artery disease. Nitric Oxide 2001, 5(4):343-348.

17. Salazar LA, Hirata MH, Giannini SD, Forti N, Diament J, Lima TM, Hirata RD: Seven DNA polymorphisms at the candidate genes of atherosclerosis in Brazilian women with angiographically documented coronary artery disease. Clin Chim Acta 2000, 300(1-2):139-149.

18. Grilo A, Ruiz-Granados ES, Moreno-Rey C, Rivera JM, Ruiz A, Real LM, Saez ME: Genetic analysis of candidate SNPs for metabolic syndrome in obstructive sleep apnea (OSA). Gene 2013, 521(1):150-154.

19. Zanchi A, Moczulski DK, Hanna LS, Wantman M, Warram JH, Krolewski AS: Risk of advanced diabetic nephropathy in type 1 diabetes is associated with endothelial nitric oxide synthase gene polymorphism. Kidney Int 2000, 57(2):405-413.

20. Wang $X \mathrm{~L}$, Wang J: Endothelial nitric oxide synthase gene sequence variations and vascular disease. Mol Genet Metab 2000, 70(4):241-251.

21. Zintzaras E, Kitsios G, Stefanidis I: Endothelial NO synthase gene polymorphisms and hypertension: a meta-analysis. Hypertension 2006 48(4):700-710

22. Prudente S, Morini E, Larmon J, Andreozzi F, Di Pietro N, Nigro A, Gervino EV, Mannino GC, Bacci S, Hauser TH, et al: The SH2B1 obesity locus is associated with myocardial infarction in diabetic patients and with $\mathrm{NO}$ synthase activity in endothelial cells. Atherosclerosis 2011, 219(2):667-672.

23. Bohm F, Pernow J: The importance of endothelin-1 for vascular dysfunction in cardiovascular disease. Cardiovascular res 2007, 76(1):8-18.

24. Inoue A, Yanagisawa M, Kimura S, Kasuya Y, Miyauchi T, Goto K, Masaki T: The human endothelin family: three structurally and pharmacologically distinct isopeptides predicted by three separate genes. Proc Natl Acad SCl USA 1989, 86(8):2863-2867.

25. Colombo MG, Ciofini E, Paradossi U, Bevilacqua S, Biagini A: ET-1 Lys198Asn and $\mathrm{ET}(\mathrm{A})$ receptor $\mathrm{H} 323 \mathrm{H}$ polymorphisms in heart failure. A case-control study. Cardiology 2006, 105(4):246-252.

26. Herrmann S, Schmidt-Petersen K, Pfeifer J, Perrot A, Bit-Avragim N, Eichhorn C, Dietz R, Kreutz R, Paul M, Osterziel KJ: A polymorphism in the endothelin-A receptor gene predicts survival in patients with idiopathic dilated cardiomyopathy. Eur Heart J 2001, 22(20):1948-1953.

27. Telgmann R, Harb BA, Ozcelik C, Perrot A, Schonfelder J, Nonnenmacher A, Brand M, Schmidt-Petersen K, Dietz R, Kreutz R, et al: The G-231A polymorphism in the endothelin-A receptor gene is associated with lower aortic pressure in patients with dilated cardiomyopathy. Am J Hypertens 2007, 20(1):32-37.

28. Li H, Louey JW, Choy KW, Liu DT, Chan WM, Chan YM, Fung NS, Fan BJ, Baum L, Chan JC, et al: EDN1 Lys198Asn is associated with diabetic retinopathy in type 2 diabetes. Molecular vision 2008, 14:1698-1704.
29. Yasuda H, Kamide K, Takiuchi S, Matayoshi T, Hanada H, Kada A, Yang J, Miwa Y, Yoshii M, Horio T, et al: Association of single nucleotide polymorphisms in endothelin family genes with the progression of atherosclerosis in patients with essential hypertension. J Hum Hypertens 2007, 21(11):883-892.

30. Lind L, Syvanen AC, Axelsson T, Lundmark P, Hagg S, Larsson A: Variation in genes in the endothelin pathway and endothelium-dependent and endothelium-independent vasodilation in an elderly population. Acta physiologica 2013, 208(1):88-94.

31. Gallek M, Alexander S, Crago E, Sherwood P, Horowitz M, Poloyac S, Conley Y: Endothelin-1 and Endothelin Receptor Gene Variants and Their Association With Negative Outcomes Following Aneurysmal Subarachnoid Hemorrhage. Biological research for nursing; 2012

32. Buck D, Diefenbach K, Penzel T, Malzahn U, Roots I, Fietze I: Genetic polymorphisms in endothelin-receptor-subtype-a-gene as susceptibility factor for obstructive sleep apnea syndrome. Sleep medicine 2010, 11(2):213-217

33. Montgomery-Downs HE, O'Brien LM, Gulliver TE, Gozal D: Polysomnographic characteristics in normal preschool and early school-aged children. Pediatrics 2006, 117(3):741-753.

34. Rechtschaffen A, Kales A: A manual of standardized terminology, techniques and scoring system for sleep stages of human subjects. Washington DC: Government Printing Office, National Institute of Health: Allan Rechtschaffen and Anthony Kales, editors, 1st edn; 1968.

35. Berry RB, Budhiraja R, Gottlieb DJ, Gozal D, Iber C, Kapur VK, Marcus CL Mehra R, Parthasarathy S, Quan SF, et al: Rules for scoring respiratory events in sleep: update of the 2007 AASM manual for the scoring of sleep and associated events. Deliberations of the sleep apnea definitions task force of the American academy of sleep medicine. J Clin Sleep Med 2012, 8(5):597-619.

36. National High Blood Pressure Education Program Working Group on High Blood Pressure in C, Adolescents: The fourth report on the diagnosis, evaluation, and treatment of high blood pressure in children and adolescents. Pediatrics 2004, 114(2 Suppl 4th Report):555-576.

37. Bhattacharjee R, Alotaibi WH, Kheirandish-Gozal L, Capdevila OS, Gozal D: Endothelial dysfunction in obese non-hypertensive children without evidence of sleep disordered breathing. BMC pediatrics 2010, 10:8.

38. Kheirandish-Gozal L, Bhattacharjee R, Kim J, Clair HB, Gozal D: Endothelial progenitor cells and vascular dysfunction in children with obstructive sleep apnea. Am J Respir Crit Care Med 2010, 182(1):92-97.

39. Wahlberg E, Olofsson P, Swendenborg J, Fagrell B: Changes in postocclusive reactive hyperaemic values as measured with laser Doppler fluxmetry after infrainguinal arterial reconstructions. Eur J Vasc Endovasc Surg 1995, 9(2):197-203.

40. Keating BJ, Tischfield S, Murray SS, Bhangale T, Price TS, Glessner JT, Galver L, Barrett JC, Grant SF, Farlow DN, et al: Concept, design and implementation of a cardiovascular gene-centric $50 \mathrm{k}$ SNP array for large-scale genomic association studies. PLoS One 2008, 3(10):e3583.

41. Livak KJ, Schmittgen TD: Analysis of relative gene expression data using real-time quantitative $\mathrm{PCR}$ and the 2(-Delta Delta $\mathrm{C}(\mathrm{T})$ ) Method. Methods (San Diego, Calif 2001, 25(4):402-408.

42. Gabriel SB, Schaffner SF, Nguyen H, Moore JM, Roy J, Blumenstiel B, Higgins J, DeFelice M, Lochner A, Faggart M, et al: The structure of haplotype blocks in the human genome. Science 2002, 296(5576):2225-2229.

43. Lewontin RC: On measures of gametic disequilibrium. Genetics 1988 120(3):849-852.

44. Schaid DJ, Rowland CM, Tines DE, Jacobson RM, Poland GA: Score tests for association between traits and haplotypes when linkage phase is ambiguous. Am J Hum Genet 2002, 70(2):425-434.

45. Brunner F, Bras-Silva C, Cerdeira AS, Leite-Moreira AF: Cardiovascula endothelins: essential regulators of cardiovascular homeostasis. Pharmacol Ther 2006, 111(2):508-531.

46. Valle Jimenez M, Estepa RM, Camacho RM, Estrada RC, Luna FG, Guitarte FB: Endothelial dysfunction is related to insulin resistance and inflammatory biomarker levels in obese prepubertal children. Eur J Endocrinol 2007, 156(4):497-502.

47. Khalyfa A, Kheirandish-Gozal L, Capdevila OS, Bhattacharjee R, Gozal D: Macrophage migration inhibitory factor gene polymorphisms and plasma levels in children with obstructive sleep apnea. Pediatr Pulmonol 2012, 47(10):1001-1011. 
48. Bhushan B, Khalyfa A, Spruyt K, Kheirandish-Gozal L, Capdevila OS, Bhattacharjee R, Kim J, Keating B, Hakonarson H, Gozal D: Fatty-acid binding protein 4 gene polymorphisms and plasma levels in children with obstructive sleep apnea. Sleep medicine 2011, 12(7):666-671.

49. Khalyfa A, Serpero LD, Kheirandish-Gozal L, Capdevila OS, Gozal D: TNF-alpha gene polymorphisms and excessive daytime sleepiness in pediatric obstructive sleep apnea. J Pediatr 2011, 158(1):77-82.

50. Pierola J, Alemany A, Yanez A, De-la-Pena M, Sanchez-de-la-Torre M, Esquinas C, Perez-Gutierrez C, Burguera B, Barbe F, Barcelo A: NADPH oxidase p22phox polymorphisms and oxidative stress in patients with obstructive sleep apnoea. Respir Med 2011, 105(11):1748-1754.

51. Pierola J, Barcelo A, de la Pena M, Barbe F, Soriano JB, Sanchez Armengol A, Martinez C, Agusti A: beta3-Adrenergic receptor Trp64Arg polymorphism and increased body mass index in sleep apnoea. Eur Respir J 2007, 30(4):743-747

52. Zintzaras $\mathrm{E}$ : he generalized odds ratio as a measure of genetic risk effect in the analysis and meta-analysis of association studies. Stat Appl Genet Mol Biol 2010, 9:21

53. Zintzaras E, Santos M: Estimating the mode of inheritance in genetic association studies of qualitative traits based on the degree of dominance index. BMC Med Res Methodol 2011, 11:171.

54. Khalyfa A, Capdevila OS, Buazza MO, Serpero LD, Kheirandish-Gozal L, Gozal D: Genome-wide gene expression profiling in children with non-obese obstructive sleep apnea. Sleep medicine 2009, 10(1):75-86.

55. Kaparianos A, Sampsonas F, Karkoulias K, Spiropoulos K: Obstructive sleep apnoea syndrome and genes. Neth J Med 2006, 64(8):280-289.

56. Atkeson A, Yeh SY, Malhotra A, Jelic S: Endothelial function in obstructive sleep apnea. Prog Cardiovasc Dis 2009, 51(5):351-362.

57. Atkeson A, Jelic S: Mechanisms of endothelial dysfunction in obstructive sleep apnea. Vasc Health Risk Manag 2008, 4(6):1327-1335.

58. Gozal D: Sleep, sleep disorders and inflammation in children. Sleep med 2009, 10(Suppl 1):S12-16.

59. Yue W, Liu H, Zhang J, Zhang X, Wang X, Liu T, Liu P, Hao W: Association study of serotonin transporter gene polymorphisms with obstructive sleep apnea syndrome in Chinese Han population. Sleep 2008, 31(11):1535-1541.

60. Riha RL, Brander P, Vennelle M, McArdle N, Kerr SM, Anderson NH, Douglas NJ: Tumour necrosis factor-alpha (-308) gene polymorphism in obstructive sleep apnoea-hypopnoea syndrome. Physiology Eur Respir J 2005 26(4):673-678.

61. Khalyfa A, Bhushan B, Hegazi M, Kim J, Kheirandish-Gozal L, Bhattacharjee R, Capdevila OS, Gozal D: Fatty-acid binding protein 4 gene variants and childhood obesity: potential implications for insulin sensitivity and CRP levels. Lipids Health Dis 2010, 9:18.

62. Chmielewska I, Molina-Martinez FJ, Massot-Cladera M, Diaz-Navarro R, Martinez-Garcia AB: [Vagal cephalalgia: description of a new case report] Rev Neurol 2012, 55(6):379-380.

63. Mishra HK, Sharma SK, Sreenivas V: Angiotensin-converting enzyme gene polymorphism in north Indian population with obstructive sleep apnea. Sleep Breath 2013, 17(3):1029-1037.

64. Bouzigon E, Monier F, Boussaha M, Le Moual N, Huyvaert H, Matran R, Letort S, Bousquet J, Pin I, Lathrop M, et al: Associations between nitric oxide synthase genes and exhaled NO-related phenotypes according to asthma status. PLoS One 2012, 7(5):e36672.

65. Duckworth L, Hsu L, Feng H, Wang J, Sylvester JE, Kissoon N, Sandler E, Lima JJ: Physician-diagnosed asthma and acute chest syndrome: associations with NOS polymorphisms. Pediatr Pulmonol 2007 42(4):332-338.

66. Galecki P, Maes M, Florkowski A, Lewinski A, Galecka E, Bienkiewicz M, Szemraj J: Association between inducible and neuronal nitric oxide synthase polymorphisms and recurrent depressive disorder. J Affect Disord 2011, 129(1-3):175-182.

67. Kavya R, Saluja R, Singh S, Dikshit M: Nitric oxide synthase regulation and diversity: implications in Parkinson's disease. Nitric Oxide 2006, 15(4):280-294.

68. Zeng Z, Li L, Zhang Z, Li Y, Wei Z, Huang K, He L, Shi Y: A meta-analysis of three polymorphisms in the endothelial nitric oxide synthase gene (NOS3) and their effect on the risk of diabetic nephropathy. Human genetics 2010 127(4):373-381.
69. Manso H, Krug T, Sobral J, Albergaria I, Gaspar G, Ferro JM, Oliveira SA, Vicente AM: Variants within the nitric oxide synthase 1 gene are associated with stroke susceptibility. Atherosclerosis 2012, 220(2):443-448.

70. Levin ER: Endothelins. N Engl J Med 1995, 333(6):356-363.

71. Kohan DE, Rossi NF, Inscho EW, Pollock DM: Regulation of blood pressure and salt homeostasis by endothelin. Physiol Rev 2011, 91(1):1-77.

72. Castro MG, Rodriguez-Pascual F, Magan-Marchal N, Reguero JR, Alonso-Montes C, Moris C, Alvarez V, Lamas S, Coto E: Screening of the endothelin1 gene (EDN1) in a cohort of patients with essential left ventricular hypertrophy. Ann Hum Genet 2007, 71(Pt 5):601-610.

73. Zhu G, Carlsen K, Carlsen KH, Lenney W, Silverman M, Whyte MK, Hosking L, Helms P, Roses AD, Hay DW, et al: Polymorphisms in the endothelin-1 (EDN1) are associated with asthma in two populations. Genes and immunity 2008, 9(1):23-29.

74. Amin R, Somers VK, McConnell K, Willging P, Myer C, Sherman M, McPhail G, Morgenthal A, Fenchel M, Bean J, et al: Activity-adjusted 24-hour ambulatory blood pressure and cardiac remodeling in children with sleep disordered breathing. Hypertension 2008, 51(1):84-91.

75. de Frutos S, Caldwell E, Nitta CH, Kanagy NL, Wang J, Wang W, Walker MK, Gonzalez Bosc LV: NFATc3 contributes to intermittent hypoxia-induced arterial remodeling in mice. Am J Physiol Heart Circ Physiol 2010, 299(2):H356-363.

76. Ci S, Li H, Song H: [Effects of blood pressure day-nocturnal rhythm and endothelin in patients of sleep apnea syndrome]. Zhonghua Jie He He Hu Xi Za Zhi 1996, 19(4):229-231.

77. Saarelainen S, Seppala E, Laasonen K, Hasan J: Circulating endothelin-1 in obstructive sleep apnea. Endothelium 1997, 5(2):115-118.

doi:10.1186/1755-8794-6-29

Cite this article as: Chatsuriyawong et al:: Polymorphisms in nitric oxide synthase and endothelin genes among children with obstructive sleep apnea. BMC Medical Genomics 2013 6:29.

\section{Submit your next manuscript to BioMed Central and take full advantage of:}

- Convenient online submission

- Thorough peer review

- No space constraints or color figure charges

- Immediate publication on acceptance

- Inclusion in PubMed, CAS, Scopus and Google Scholar

- Research which is freely available for redistribution 